\title{
Educação na América Latina: pressupostos e alcance de estudos comparativos
}

\author{
Célio da Cunha
}

Resumo:

O presente trabalho é parte de um estudo comparativo mais amplo de políticas educacionais dos países-membros da União de Nações Sul-Americanas (Unasul), um bloco de colaboração e atividades comuns. Iniciando pelo contexto histórico, social, econômico e político dos países-membros, verifica-se a importância de estudar o passado histórico, que influencia fortemente o presente e o futuro. Com isso, se desenha no continente um mosaico de similaridades e diferenças nas sociedades e na educação. Todavia, apesar das diversidades dos países, desde o período colonial aos tempos atuais, como diferenças da estrutura dos Estados, a exemplo dos unitários e federativos, constatam-se problemas educacionais comuns. Um deles é o contínuo ajustamento às cambiantes situações do mundo hoje e das suas estruturas políticas à democracia. Recomenda-se o avanço dos estudos comparados sobre a América Latina, para melhor compreender os seus problemas da sua educação e as suas perspectivas de soluções.

\section{Palavras-chave:}

educação comparada; políticas educacionais; América Latina; União de Nações Sul-Americanas (Unasul). 


\section{La educación en América Latina: presupuestos y alcance de estudios comparativos}

Resumen: Este trabajo es parte de un estudio comparativo más amplio sobre las políticas educativas de los paísesmiembros de la Unión de Naciones Suramericanas (Unasur), un bloque de cooperación y actividades comunes. Con foco inicial en el contexto histórico, social, económico y político de los países-miembros, se verifica la importancia de estudiar el pasado histórico, que influencia fuertemente el presente y el futuro. Así, se diseña en el continente un mosaico de similaridades y diferencias en las sociedades y en la educación. Sin embargo, a pesar de las diversidades entre países, desde el período colonial hasta los tiempos actuales, a ejemplo de las diferencias de la estructura de los Estados, como unitarios y federativos, se constatan problemas educativos comunes. Uno de ellos es su continuo ajuste a las cambiantes situaciones del mundo de hoy y de sus estructuras políticas a la democracia. Se recomienda el avance de los estudios comparados sobre la América Latina, con el fin de mejor comprender sus problemas educativos, así como sus perspectivas de soluciones.

Palabras clave: educación comparada; políticas educativas; América Latina; Unión de Naciones Suramericanas (Unasur)

\section{Education in Latin America: assumptions and dimension of comparative studies}

Abstract: This paper is part of wider comparative study on the educational policies of member countries of the Union of South American Nations (Unasur in its Spanish acronym), a group of mutual cooperation and common activities. It approaches in its first part the historical, social, economic and political context of the member countries, revealing the importance of analysing their historical past, strongly influencing their present and future. Therefore, the continent is a mosaic of similarities and differences among societies and education. However, despite the diversities among these countries since colonization, as, e.g., the differences between unitary and federative states, we found common educational questions. One of them is their continuous adjustment to changing circumstances today, as well as of political structures to democracy. We recommend further advance of comparative studies on Latin America, aiming to better understanding their education problems, as well as their solution perspectives.

Key words: comparative education; educational policies; Latin America; Union of South American Nations (Unasur)

\section{L'éducation en Amérique Latine: présuppositions et portées des études compartives}

Résumé : Ce travail intègre une étude comparative plus étendue sur les politiques éducatives des pays-membres de I'Union des Nations Sudaméricaines (Unasur, selon l'acronyme espagnol), un bloc pour la coopération et des activités communes. Une approche introductoire sur le contexte historique, social, économique et politique de ses pays membres révèle la relevance de l'approche de leur passé historique, avec sa forte influence sur son présent et son future. Ainsi, ce continent est constitué comme un mosaïque de similarités et de différences dans l'éducation. Cependant, en dépit des diversités parmi les pays, dès les temps de la colonisation jusqu'aujourd'hui, comme les différentes structures des États, unitaires et fédératifs, se vérifient des problèmes éducatifs communs. Un de ses problèmes est le permanent ajustement aux changements du monde actuel et de ses structures politiques à la démocratie. On recommande l'avance des études comparatives sur l'Amérique Latine, pour une meilleure compréhension de ses questions éducatives et de ses perspectives pour leur solution.

Mots clés: éducation comparée; politiques éducatives; Amérique Latine; Union des Nations Sud-Américaines (Unasur) 
Em 2014, como parte de um estudo comparativo entre os países da União das Nações Sul-Americanas (Unasul), foi solicitado aos Ministérios da Educação a produção de um relatório descritivo sobre as políticas de educação então vigentes, incluindo informações sobre diversos aspectos, entre eles, gestão educacional, qualidade do ensino, magistério e financiamento. Com base nas informações contidas nesses documentos foi produzido um livro ${ }^{1}$ que sintetizou as políticas e inovações em curso, bem como apresentou uma proposta de cooperação técnica entre os Ministérios da Educação dos países que integram o bloco da Unasul. Esse projeto fundamentava-se no pressuposto de inegável contribuição de estudos comparativos para a cooperação técnica e solidária entre os países da América do Sul. Nicholas Hans, na conclusão de sua obra clássica "Educação comparada", após analisar a educação em quatro nações - Estados Unidos da América, Inglaterra, França e Rússia - afirmou que todas elas estão tentando ajustar as tradições herdadas aos ideais democráticos e à estrutura econômica da sociedade que está mudando, sendo que os mesmos problemas agitam os espíritos dos reformadores educacionais, como ainda as velhas fontes da teoria educacional que são estudadas mundo afora (Hans, 1971). Apesar de decorridos quase 70 anos da primeira edição dessa obra, em Londres, 1951, a argumentação permanece atual, pois, os sistemas educacionais da América Latina, como de outros continentes, também se defrontam hoje com o desafio de acompanhar e se adaptar às mudanças e transformações que se registram em todo o mundo em ritmo, velocidade e contornos sem precedentes.

Desse modo, a partir dos relatórios mencionados, do estudo subsequente realizado e em fontes adicionais, o presente artigo tem o objetivo de discutir o alcance e limitações de estudos comparados na região com vistas às suas perspectivas e importância para a ideia de intercâmbio e cooperação entre os Ministérios da Educação dos países da Unasul. Tem ainda o objetivo de qualificar social e culturalmente a cooperação no sentido de que os rumos e contornos a serem tomados pelas políticas de educação não deixem em segundo plano as marcas emblemáticas sedimentadas ao longo da história dos países e de seus respectivos contextos. Na esteira dessa linha, será apresentado inicialmente um panorama geral do contexto socioeconômico e cultural da América do Sul, seguido de exemplos e discussão simultânea das políticas educacionais e reflexões a propósito da cooperação e possíveis avanços para a ideia de integração. A importância do contexto cultural e socioeconômico sobressai e foi ressaltada por Kandel em sua antológica afirmação de que um sistema de educação "traz em si a marca de certas influências secretas da vida nacional" (Kandel, 1960, p. 25). 


\section{Contexto social, econômico e cultural}

A América do Sul não constitui um espaço homogêneo. São muitas as diferenças e contrastes. Como ser integrista, pergunta Alain Touraine, em um continente que não possui quase nenhuma homogeneidade cultural, nem étnica, nem religiosa, nem ideológica? Todavia, segundo esse estudioso, pode-se falar num modo latino-americano de desenvolvimento, isto é, uma combinação de racionalismo econômico e de mobilização política, social e cultural própria do continente (Touraine, 1989). Para a construção desse "modo de ser" admitido por Touraine, o impulso do intercâmbio entre os Ministérios da Educação com a realização simultânea de análises comparativas entre diversos componentes das políticas de educação adotadas, pode contribuir para a revisão de caminhos e inspirar mudanças prospectivas. Daí a importância de estudos aprofundados sobre as diferenças e os diversos contextos da região como condição imprescindível para ações programadas de cooperação e intercâmbio. No aprofundamento do estudo das diferenças reside a possibilidade de identificação de pontos de convergência.

A necessidade e a relevância do conhecimento do contexto vem sendo ressaltada por diversos estudiosos. Sonia Mehta, por exemplo, afirma que muitas críticas oriundas das ciências sociais apontaram que os iluministas do chamado Século das Luzes, com toda a sua elegância e promessas da razão e da ideologia humanitária, moldaram uma sociedade hostil às diferenças, à diversidade e às culturas não ocidentais, vistas como culturas do conhecimento não científico. Neste caso, o privilégio atribuído à verdade científica acima de todas as outras limita as opções epistemológicas e a compreensão integral da diversidade humana (Mehta, 2012). Não é outra a posição de Crossley ao argumentar que são os fatores contextuais e a consciência crescente sobre sua importância na pesquisa que dão sustentação a muitos dos principais desenvolvimentos de nosso tempo (Crossley, 2015). Outro pesquisador de estudos comparativos chega mesmo a dizer que o papel crucial desempenhado pelo contexto pode minar a dominância do Estado-nação como unidade de análise nos estudos comparados de políticas educacionais, pois as forças globais estão alterando dramaticamente a função do Estado na educação e requerendo que maior atenção seja dispensada aos fatores presentes nos níveis supranacionais e subnacionais (Yang, 2015).

A importância de considerar os contextos políticos, econômicos, culturais, regionais e locais remete à ideia de América Latina e de sua história. Como lembrou Mix (2004), a política de colonização teve a função de marginalizar ou mesmo apagar a cultura original das nações que habitavam a América. Colonizados por séculos, tiveram que aprehender un nuevo espacio para representar al mundo, un espacio donde el dominio de la pespectiva europea los obligaba a negar el tiempo y a sacrificar la historia (...). Face a esse contexto histórico de desprezo pela cultura e saberes dos 
povos autóctones, muitos transplantes impositivos e hegemônicos foram responsáveis pelo emudecimento de vozes e iniciativas emancipadoras. Nessa direção, a afirmação clássica de M. Sadler, pioneiro dos estudos comparativos na área da educação, de que as mudas transplantadas carregam micro-organismos que podem alterar um ecossistema, poderá ser factível admitir que muitas dessas plantas transportadas por Colombo ou por Pedro A. Cabral, alteraram e obliteraram concepções e modos de vida de inúmeras nações que habitavam o novo mundo (Cunha, no prelo). Como salientou Mix, [...] "desde el principio se acuñaron dos efigies de americano: el salvaje idealizado, noble, y el antropófago caníbal: terrible cromo de la barbarie. Con ellos se desarrolló un conjunto de atributos estereotipados, que tenían más valor como discurso sobre el hombre americano que como retrato" (Mix, 1992, p. 248).

A propósito das reflexões de Mix sobre as considerações estereotipadas do homem americano que ainda chegam aos nossos dias, um parêntese se torna oportuno. Francisco Bethencourt, em admirável obra sobre o racismo, ao examinar as pesquisas científicas sobre a variedade dos seres humanos, admitiu que, a partir de meados do século XIX, elas se tornaram ideologicamente agressivas e politicamente empenhadas. A esta nova etapa de desenvolvimento de estudos no setor ele denominou de racialismo científico, na medida em que ocorreu um esforço científico para justificar e reificar as divisões, bem como as hierarquias de raças, que supostamente seriam inatas, imutáveis e perpétuas (Bethencourt, 2015). Uma das teorias analisadas por ele, a de Arthur Gobineau e que influenciou muito o Brasil, argumentava que a idade de ouro da pureza racial passara havia muito tempo. A história do mundo envolvia a mistura constante de povos, com os elementos mais capazes a providenciarem o impulso inicial, até serem assoberbados pelos elementos mais baixos da mistura, o que levava ao declínio inevitável (Bethencourt, 2015).

Daí a importância de pensar as políticas de educação a partir dos delineamentos históricos e culturais da América Latina, de modo a facilitar a compreensão da situação presente. Assim sendo, devido às diferenças já mencionadas, constitui tarefa das mais complexas, arriscar uma síntese de visão global do continente sul-americano nas dimensões econômica, social e cultural. Será sempre parcial e incompleta. O que há de comum é uma história colonial (apesar das diferenças entre a colonização portuguesa e espanhola) e, em tempos mais recentes, a forte presença da ideologia neoliberal que fragilizou o Estado e contribuiu para o agravamento das questões sociais. Argumentava-se com frequência que o Estado representava um entrave ao desenvolvimento das forças produtivas. Em decorrência, os postulados neokeynesianos foram deixados de lado em favor dos princípios liberais da economia (Castro, 2012) . O outono do ciclo de radicalização neoliberal, no final do século XX, foi marcado por crises econômicas e sociais na maior parte dos países da região. Sucessivos abalos financeiros assolaram o continente no período de 1994 a 2003, desfazendo em boa parte as ilusões do 
"Consenso de Washington". Ataques especulativos contra as moedas, crise nos balanços de pagamento, fuga de capitais e moratória das dívidas, estão entre os efeitos que acirraram os movimentos sociais de vários países. Grande parte da população foi às ruas para cobrar dívidas históricas, como a da discriminação contra os indígenas e afrodescendentes (Paulino \& Pires, 2012, p. 407).

No período que se segue, em vários países, governantes mais à esquerda chegaram ao poder e, mais sensíveis ao desenvolvimento social e aproveitando em muitos casos o mercado mundial favorável das commodities (sobretudo agrícolas e minerais), procederam a significativos investimentos na área social e conseguiram reduzir a pobreza e ampliar a oferta de educação básica, conforme mostra o relatório Panorama Social da América Latina, da Comissão Econômica para a América Latina e o Caribe (Cepal) (2015) . Lamentavelmente, conforme argumentam os autores citados, Paulino e Pires (2012), as oportunidades se abrem e depois de certo tempo se fecham. Com o advento da crise iniciada em Wall Street, em 2008, a maioria dos países da América do Sul sofreu seus efeitos perversos. Não estavam com a economia preparada para enfrentar a crise e as consequências logo surgiram, algumas severas e recessivas como a do Brasil. Após tantas idas e vindas da economia, o cenário no ano de 2017 foi assim sintetizado pela Cepal no Relatório Panorama Social de América Latina (Cepal, 2017, p. 11):

Los análisis de la Cepal sobre el desarrollo económico y social han señalado que las economías latinoamericanas y caribeñas históricamente se han caracterizado por la presencia de una marcada heterogeneidad estructural que está, en gran medida, en la base de los altos niveles de desigualdad social que son típicos de la región. La estructura productiva, poco diversificada y altamente heterogénea, en la que los sectores de baja productividad generan aproximadamente un 50\% del empleo, constituye un determinante fundamental de la desigualdad. El mercado de trabajo es el eslabón clave que vincula esa estructura productiva con una alta desigualdad del ingreso de los hogares, relacionada con una distribución muy diferenciada de las ganancias de la productividad y con un acceso fuertemente estratificado al empleo de calidad y a la protección social.

Não obstante os progressos recentes, conforme já foi ressaltado, a América Latina continua a ostentar, conforme mostra a análise da Cepal, uma das piores distribuições de renda do mundo, à qual se acrescentam múltiplas desigualdades que se reforçam mutuamente, destacando-se entre elas: desigualdades de renda, de educação e de saúde, brechas em matéria de desenvolvimento de capacidades, inserção no mundo do trabalho, acesso a sistemas de proteção social, questões de gênero e etnia, 
participação política dos cidadãos. A igualdade como valor central foi excluída do léxico do desenvolvimento por décadas, pois o modelo norteado pela primazia do mercado e redução das funções sociais do Estado, foi mesmo obstado (Cepal, 2014). O documento da Cepal destaca que a igualdade associada à dignidade não constitui novidade. Está na origem da modernidade republicana e da llustração e configura-se como a chave da autonomia com reconhecimento recíproco e justiça distributiva (Cepal, 2014). Registre-se, por oportuno, que os encantos da llustração com as ideias de justiça e solidariedade, estão longe de se converterem em fatos da vida real.

A Cepal, diante do cenário de acentuadas desigualdades na região, lançou em 2014, em Lima, Peru, o documento Pactos para la igualdad, que, em seus comentários finais, indica algumas questões fundamentais para as políticas de educação. Em primeiro lugar, assinala que a compreensão das distintas faces da desigualdade na América Latina, não deixando de considerar os avanços obtidos dos últimos anos, permite colocar algumas interrogações sobre o futuro. Como os avanços estão vinculados a ciclos econômicos favoráveis, há o risco da reversão (Cepal, 2014). Disso deriva a importância de enfrentamento integrado e multidimensional. De forma mais explícita, conclui o documento:

Sin duda esta perspectiva multidimensional reclama, a su vez, un correlato en materia de políticas a fin de progresar hacia una mayor igualdad para desarrollar capacidades y utilizarlas en la esfera productiva y en proyectos de vida, tanto personales como colectivos. A la interrelación en los hechos debe corresponder un enfoque integrado de políticas que permita potenciar sinergias y mitigar círculos viciosos. Así, por ejemplo, las políticas habitacionales para prevenir el hacinamiento pueden redundar en una mayor igualdad de logros y aprendizajes en educación; las políticas de infraestructura en las escuelas pueden llevar a una mayor difusión de acceso a las TIC para niños y jóvenes de familias de escasos recursos; las políticas para el pleno ejercicio de los derechos reproductivos pueden prevenir la deserción escolar de adolescentes y, inversamente, las políticas de retención y progresión escolar amplían las posibilidades en cuanto a proyectos de vida de las y los adolescentes; la extensión de servicios de guarderías y de educación inicial puede acompañarse de programas nutricionales para niños en situación de riesgo, mientras que los programas de control nutricional en el primer año influyen, más adelante, en el aprendizaje escolar (Cepal, 2014, p. 120).

Esse texto da Cepal coloca em evidência a urgência da educação. A proposta de um enfoque integrado de políticas demanda ações e políticas compartilhadas, no seio 
do qual emerge a relevância de estudos comparados que podem apontar novos horizontes de inovação e mudança. É certo que muitos teóricos da educação comparada hesitam nas relações entre estudos comparados e políticas da educação. Entretanto, com o impulso tomado pelo processo de internacionalização da educação e com a crescente mobilidade de especialistas e de estudantes que se deslocam para vários países para conhecer experiências educacionais, a realização de estudos acadêmicos pode contribuir inclusive para evitar equívocos que por vezes podem ocorrer em situações de transplante de experiências, sem a necessária "redução sociológica", para usar o título da obra clássica de Guerreiro Ramos (1965).

$\mathrm{Na}$ área da educação, o estudo da Cepal sobre as desigualdades sociais reconhece os avanços de cobertura obtidos nos últimos decênios. Apesar disso, segue existindo grande heterogeneidade entre e dentro dos países. São déficits que não estão relacionados apenas com o nível de desenvolvimento dos países, como também devido a fatores internos de desigualdade. No caso, por exemplo, de jovens entre 20 e 24 anos de idade que concluíram a educação secundária na América Latina, entre o primeiro e o quinto quintil pode ocorrer uma variação de 34\% a 80\%. Na educação superior os déficits são ainda maiores. Isto significa que nos países da América do Sul existem segmentos populacionais com acentuados déficits educacionais que estão relacionados com outras esferas fundamentais como o trabalho remunerado, a saúde, a moradia, a mortalidade infantil e a esperança de vida (Cepal, 2017). Também no plano interno dos países as diferenças são enormes. Diferenças que podem ser devidas não somente às desigualdades regionais, como também ao desempenho de políticas educacionais. No Brasil, por exemplo, pode-se perguntar e mesmo estudar por que os avanços educacionais que estão sendo alcançados pelo Estado no Ceará, localizado numa região historicamente pobre, não estão sendo possíveis em algumas outras unidades da federação?

Além dos déficits de cobertura, importa sobrelevar a distância cognitiva existente entre os países da América do Sul e os países mais avançados. Tomando como referência a avaliação conduzida pela OCDE, por intermédio do Programa Internacional de Avaliação de Estudantes (Pisa), na área de ciências, as diferenças continuam preocupantes, malgrado alguns progressos nos últimos anos. No Pisa 2015 (Brasil, 2016), enquanto países da União Europeia e da Ásia Oriental obtiveram pontuações médias altas, como a Finlândia (531), Canadá (528) e Coreia do Sul (516), países sul-americanos não conseguiram alcançar notas significativas, como o Chile (447), Uruguai (435), Colômbia (416) e Brasil (401). Nesse mesmo ano, Portugal, que tem feito grandes esforços nos últimos anos, atingiu 501 pontos. No nível mais alto da escala de proficiência (nível 6), que permite aos estudantes recorrer a uma série de ideias e conceitos científicos da física, das ciências da vida, da terra e do espaço, assim como usar conhecimentos de conteúdo procedimentais e epistemológicos para formular hipóteses 
explicativas para novos fenômenos científicos ou para fazer suposições, o percentual de estudantes brasileiros atingiu somente 0,02\% e no nível 5 de proficiência (capacidade para usar ideias ou conceitos científicos abstratos para explicar fenômenos incomuns e mais complexos), o resultado foi de 0,65\%, sendo que neste nível, a média dos países da Organização para a Cooperação e Desenvolvimento Econômico (OCDE ) foi de $6,67 \%$. Em matemática, $70,3 \%$ dos estudantes brasileiros estão abaixo do nível 2 de proficiência, que requer capacidade para interpretar e reconhecer situações em contextos que não exigem mais do que uma inferência direta (Brasil, 2016).

É certo que a utilização de avaliações em larga escala, como a do Pisa, exige cuidados e ponderações devido aos seus limites. Há certamente o problema do contexto, pois, como afirmou um especialista, os comportamentos humanos são influenciados pela cultura, sendo "difícil sustentar conclusões de que as coisas pioraram ou se tornaram gradativamente melhores no decorrer do tempo. É muito mais provável que qualquer aspecto do sistema de educação simplesmente reflita forças, processos e tendências presentes na sociedade e na cultura no sentido mais amplo, naquele exato momento da história" (Mason, 2015, p. 283).

Nesse caso, as perspectivas de alunos oriundos de culturas diferentes precisam ser consideradas. Em relação ao contexto, assinala Yang, é muito comum encontrar estudos de políticas educacionais que o ignora, sendo possível identificar uma variedade de usos e abusos (Yang, 2015). Por isso mesmo, Leung e Park advertem que é muito difícil construir medidas de desempenho. E mesmo que isso seja possível, é preciso ser bastante cauteloso ao comparar países, particularmente no ano final da educação secundária para o qual muitos horizontes das populações-alvo são bastante diferentes (Leung \& Park, 2015).

Em relação às avaliações em larga escala, António Teodoro foi mais incisivo. Afirma que os grandes inquéritos como o Trends in International Mathematics and Science Study (Timss) e o Pisa que, em alguns países são replicados no plano nacional, e a sua permanente comparação em relatórios e estudos nacionais e internacionais, pouco (ou nada) preocupados com os contextos sócio-históricos geradores desses resultados, tornaram-se uma das principais tecnologias da governança (Teodoro, 2016). De fato, essas avaliações, largamente disseminadas pela imprensa por intermédio de rankings comparativos entre os países, possui uma enorme influência nos fins da educação e no processo de formulação e execução de políticas para o setor, situação que pode contribuir para possíveis desvios de rumo e subtração de questões fundamentais que são inerentes ao conceito de educação. A rigor, toda avaliação, seja ou não em larga escala, deve possuir uma dimensão ética e ser usada como procedimento diagnóstico, com o objetivo de reunir informações indispensáveis à melhoria do ensino. Ademais, as avaliações de desempenho escolar não podem ser conduzidas de forma indissociável do próprio conceito de educação, que precisa ser formulado a partir não somente de 
demandas emergenciais, como também no valioso acervo de reflexões sobre pensamento pedagógico de pensadores, filósofos, sociólogos (...) que ao longo da história dedicaram o melhor de suas energias espirituais para mostrar a relevância da educação na vida das pessoas e dos países.

Quando Edgar Morin escreveu "Os 7 saberes necessários à educação do futuro", chamando a atenção para as aprendizagens que ele considerava fundamentais para o nosso tempo, - o ensino da condição humana, o conhecimento pertinente, a identidade terrena, o ensino das incertezas, a compreensão e a ética do gênero humano -, na primeira frase do prólogo dessa obra, com sua experiência intelectual interdisciplinar e octogenária, afirmou: "Este texto antecede qualquer guia ou compêndio de ensino. Não é um tratado sobre o conjunto das disciplinas que são ou deveriam ser ensinadas: pretende, única e essencialmente, expor problemas centrais ou fundamentais que permanecem totalmente ignorados ou esquecidos e que são necessários para se ensinar no próximo século" (Morin, 2000, p. 13).

Observe-se a convicção desse filósofo em relação a alguns componentes vitais que devem estar presentes na concepção do processo educativo, como o ensino da condição humana e da ética, que antecipam os demais, e que escapam aos programas e avaliações classificatórias, direcionadas, via de regra, para o atendimento às demandas circunstanciais e pressões do mercado competitivo.

É certo que a escola, face às transformações e mudanças da economia e da sociedade devido, sobretudo, aos avanços da ciência e da tecnologia que já engendram uma nova mudança de paradigma com o advento dos computadores quânticos, precisa acelerar o ritmo de mudanças e situar-se no circuito do tempo e acompanhar pari passu o processo evolutivo. Talvez neste ponto resida uma das questões fundamentais da pedagogia contemporânea, que pode ser sintetizada nas perguntas: para onde deve ir a educação diante das vertiginosas mudanças que estão ocorrendo e que estão sendo aceleradas em ritmo sem precedentes? Capitular diante de demandas circunstanciais postas pela acirrada competitividade por conhecimentos e mercados? Refugiar-se em posturas conservadoras, por vezes retrógradas? Ou enfrentar o desafio, mesmo em circunstâncias adversas, com vistas a não deixar à margem o que Rousseau tão brilhantemente no seu "Emilio" proclamou como objetivo essencial da educação, ou seja, formar homens, pessoas, em primeiro lugar.

Sei que são questões que poucos consideram como pertinentes. No turbilhão das aceleradas transformações em curso que submetem as pessoas a dimensões unilaterais, ou, como sublinhou Marcuse (2007, p. 41), el "impacto del progreso convierte a la razón en submisión a los hechos de la vida y a la capacidad dinámica de producir más y mayores hechos de la misma especie de vida" No contexto desse quadro existencial, sem precedentes na história e de profundas implicações para a pedagogia contemporânea, Kazamias imagina a possibilidade de construção de uma nova Paideia, com a 
aprendizagem reconceituada e reconstituída ocupando lugar de destaque no currículo da educação básica e da universidade. A argumentação de Kazamias alicerça-se no amplo espectro do que passou a ser conhecido como artes liberais. Não se trata de postura conservadora. Ao contrário, defende a ideia de uma Paideia e pedagogia reinventada que poderiam ser, de fato, empoderadoras, emancipadoras e humanizadoras, incluindo os pobres, os oprimidos e os menos favorecidos (Kazamias, 2012).

Essas reflexões, aparentemente deslocadas, são necessárias no contexto e na perspectiva de estudos comparativos na América do Sul, continente, como vimos, com acentuados contrastes sociais, econômicos e culturais, mas que, na esteira de sua aspiração maior de construção de uma comunidade de países com dimensões solidárias com fundamento em suas raízes, tal como fizeram outros países como o Japão e a Coreia do Sul, porém evitando equívocos do passado. Como asseverou Touraine, o erro seria acreditar que a América Latina decolaria mais rápido se seguisse o modelo capitalista ou o modelo socialista. Sua especificidade, ou seja, seu modelo de desenvolvimento é o de combinar fatores econômicos e fatores sociais do desenvolvimento sem se entregar aos mecanismos de mercado, com vistas à construção de uma infraestrutura moderna (Touraine, 1989).

Para essa perspectiva, estudos comparativos na área da educação podem ajudar a instaurar um clima virtuoso de cooperação entre os Ministérios da Educação da região, mas sem deixar de lado as experiências e os exemplos das nações que já lograram obter avanços expressivos nas políticas educacionais. Assim sendo, em seguida serão apresentados a partir dos relatórios dos países da Unasul, alguns exemplos de possibilidades de cooperação e integração regional, mediados por estudos comparativos e reflexões conjuntas entre gestores e especialistas da educação dos diferentes países, com ênfase na gestão, magistério, qualidade do ensino e financiamento.

Em relação à gestão dos sistemas educativos, o dilema de maior ou menor descentralização nos países que integram a Unasul sempre se sobressaiu como um desafio submetido historicamente a intermitências que dependiam muitas vezes do estilo e da vontade política de governos. Países como o Brasil e a Argentina optaram pelo regime federativo, concorrendo para esse modelo o fator extensão territorial. Trata-se de um federalismo em construção com oscilações entre maior ou menor descentralização. De certo modo, a divisão de competências entre as instâncias foi sempre objeto de conflitos e se vincula também à própria evolução das ideias democráticas no continente, pois nunca se pode esquecer que diversas ditaduras permearam e obstruíram o advento de sistemas educacionais modernos e democráticos.

A descentralização da gestão na região, por exemplo, chegou a ser vista como estratégia para alcançar maior participação dos atores locais e, por conseguinte, meIhorar a qualidade da educação. Essa estratégia foi utilizada em países como a Argentina, Brasil, Chile, Colômbia, Equador e Peru. Todavia, consoante Krawczyk e Vieira, a 
descentralização contribuiu para minimizar a responsabilidade do poder central, não obstante as diferenças significativas na regulação desse processo que vão desde a mera transferência do serviço educacional até a forte regulamentação do financiamento (Krawczyk \& Vieira, 2008). Já na Bolívia e na Guiana, a gestão é centralizada com competências descentralizadas, o mesmo ocorrendo no Paraguai e no Uruguai.

Na Argentina, a Lei de Educação Nacional determinou a responsabilidade concorrente e concertada entre o Poder Executivo Nacional por intermédio do Ministério da Educação e os poderes executivos das províncias e da Cidade Autônoma de Buenos Aires, competindo ao Conselho Federal de Educação a mediação dessa divisão de atribuições. Além disso, o Conselho Federal de Educação desse país, diferentemente do Brasil e de outros países, é presidido pelo Ministro de Estado da Educação e integrado pelos ministros provinciais. No caso do Brasil, o Conselho Nacional de Educação é composto por especialistas em educação escolhidos a partir de consultas às principais entidades do setor. Todas as suas decisões precisam ser homologadas pelo titular da Pasta.

No campo da gestão educacional, uma das questões que tem sido objeto de controvérsias, experiências e estudos diz respeito à participação do setor privado. No caso do Paraguai, o seu sistema de ensino é de responsabilidade do Estado, porém poderá ser administrado por gestão privada de pessoas, empresas, associações, instituições privadas não subvencionadas ou subvencionadas com recursos do Estado e com mediação do Ministério da Educação. Todavia, no Chile está em curso a experiência mais radical de participação do setor privado. O seu sistema de ensino é de natureza mista. Boa parte da educação chilena é composta por estabelecimentos particulares subvencionados. Porém, há a centralização da direção técnica da educação escolar e, ao mesmo tempo o funcionamento das unidades escolares é descentralizado. O modelo chileno de gestão tem despertado crescente interesse de especialistas e estudiosos, como Martin Carnoy, que coordenou uma pesquisa em que ele afirma que o "sistema de mercado" educacional herdado do regime militar continuou a influenciar a política do Chile durante toda a década de 1990. Quase 50\% dos alunos frequentam escolas particulares subvencionadas ou pagas. Apesar disso, as notas dos estudantes chilenos estão também distantes dos países mais avançados e pouco diferentes de outros países da América Latina (Carnoy, 2009).

Um aspecto que merece destaque nos modelos de gestão dos sul-americanos que também demandam estudos comparativos refere-se aos espaços de participação social existentes, que oscilam entre maior e menor abertura. No caso da Bolívia, que se define como um país plurinacional, em que se destaca o Congresso Multinacional de Educação que é convocado pelo Ministério da Educação a cada 5 anos. Além dessa instância, existe o Conselho Multinacional de Educação devido ao imperativo de participação dos povos indígenas. Já a Colômbia, desde 1994, estabeleceu em lei 
as formas de participação da sociedade civil, categorizando-as e indicando suas atribuições no planejamento educacional. Entre os atores incluídos estão a comunidade educativa formada pelos estudantes, educadores, gestores, pais e responsáveis pelos alunos; a família, por intermédio de suas associações; o Conselho Acadêmico liderado pelo diretor da escola e seus docentes; as secretarias departamentais e distritais da educação com as funções de coordenar em articulação com as instâncias centrais as políticas públicas e programas do setor; o Núcleo de Desenvolvimento Educativo, unidade operativa que tem entre suas atribuições o planejamento de pesquisas e da integração comunitária; a Junta Nacional de Educação, responsável pelo desenho das políticas de educação; as juntas departamentais e distritais da educação com a incumbência de zelar pelo cumprimento das metas estabelecidas pelo Ministério da Educação; as juntas municipais de educação, também com o objetivo de acompanhar localmente as metas fixadas; e, por último, a participação da Nação, com o Estado Nacional exercendo suas funções com o apoio do Congresso da República. A experiência da Colômbia pode ou não revelar a relevância de participação de diversos atores que se fazem presente na política de educação dos países. Como o século XXI tende a inaugurar uma era de intensificação da luta para a universalização da cidadania, a educação política e democrática, desde os primeiros anos escolares, desponta como necessidade inadiável.

Os exemplos mencionados da Bolívia e da Colômbia mostram o reconhecimento da participação social no planejamento e execução das políticas de educação. Trata-se de demanda crescente em decorrência mesmo dos avanços de democratização que ocorreram na região nos últimos decênios. Releve-se, todavia, que o excesso de instâncias pode também ampliar espaços burocráticos e retardar o fluxo de comunicação e providências inadiáveis. Sendo uma das características do tempo presente a elevada velocidade de transformações e mudanças que afetam a escola, sobreleva a necessidade de leveza e agilidade nos processos de gestão. Certamente para isso poderão contribuir reflexões e estudos conjuntos entre os Ministérios da Educação dos países da Unasul, com vistas ao exame dos diversos caminhos e opções em curso e possíveis indicações de alternativas que combinem a relevância de audiências públicas com os vários segmentos da sociedade civil e a necessidade de construir modelos de gestão que atinjam um estado de fluência ideal entre os diferentes níveis e instâncias de participação e responsabilidade formal e cidadã.

Quanto ao magistério, são muitas as diferenças entre os países no tocante à formação, carreira e remuneração, com experiências que devem e podem ser intercambiadas e estudadas conjuntamente devido à centralidade da figura do professor na melhoria da qualidade do ensino. No Uruguai, há a experiência da Administração Nacional da Educação Pública (ANEP), ente autônomo com personalidade jurídica, que coordena a política de formação e carreira do magistério. Os docentes para a educação primária 
são formados no Instituto Normal de Montevideo e nos Institutos de Formação Docente que existem em todo o país; os docentes para o ensino médio são graduados e licenciados pelo Instituto Artigas (IPA) e em Centros Regionais de Professores (CERP); e a formação dos professores para a educação técnica e profissional, está sob a responsabilidade do Instituto Normal de Ensino Técnico (INET). Também na Argentina, os professores são formados predominantemente em instituições não universitárias como as Escolas Normais, Institutos de Ensino Superior e Institutos Provinciais.

No Brasil, diferentemente do Uruguai e da Argentina, os professores para a educação básica são graduados pelas universidades, centros universitários e faculdades isoladas. A ideia de Darcy Ribeiro, inserida na Lei de Diretrizes e Bases (LDB) de 1996 (Brasil, 1996), de criação nas universidades do Instituto Normal Superior com o objetivo de permitir o indispensável enlace entre teoria e prática, não avançou, apesar de muitas iniciativas que se seguiram à promulgação da referida LDB. Como observou Carnoy, em boa parte dos países, a formação docente é realizada por universidades que são independentes do Ministério da Educação. Os cursos são realizados com base no que os docentes universitários da área da educação consideram que um professor deva saber e, via de regra, incluem dose excessiva de fundamentos teóricos. Por isso, a separação entre formação docente e monitoramento estatal das habilidades docentes cria sérios problemas na construção da capacitação docente (Carnoy, 2009). Registre-se iniciativas promissoras que estão procurando, por intermédio de uma nova orientação dos estágios supervisionados, dotar a formação docente de competências fundamentadas na indissociabilidade entre teoria e prática, de modo a formar profissionais em condições de enfrentar com êxito a complexidade dialética de uma sala de aula de crianças e adolescentes ávidas de uma escola com significado e sentido.

No Chile, a formação docente está sob a responsabilidade das universidades, sendo que, de acordo com a pesquisa conduzida por Carnoy, os estudantes de cursos de licenciatura destacaram que sua formação proporcionava oportunidades muito limitadas de praticar e desenvolver pedagogias apropriadas. Algumas estratégias, lembra esse pesquisador, como as de orientação e supervisão, podem fazer diferença e tornar o processo formativo mais eficaz. Quando a tutoria e a supervisão pedagógica não se fazem presentes em programas de formação, os novos professores terão de aprender na prática, com pouca ou nenhuma orientação. A principal diferença que ele observou entre as experiências do Brasil, Chile e Cuba é a de que os estudantes cubanos são formados em núcleos supervisionados por um professor tutor que acompanha esses alunos e orienta suas futuras atividades de ensino (Carnoy, 2009). Há um outro aspecto sublinhado por Carnoy que requer novos e comparativos estudos que é o fato de os professores formadores no Brasil e no Chile terem o direito de ter quase total autonomia em suas salas de aula. Raramente são observados pelos gestores (Carnoy, 2009). 
Com referência à carreira do magistério da educação básica nos países da Unasul, o estágio atual, distante ainda de situar-se à altura da relevância do magistério para a melhoria da qualidade do ensino, apresenta características distintas e também pontos comuns que estudos posteriores poderão identificar com maior precisão. No Chile, o Estatuto Docente, de 1991, valoriza o tempo de serviço, competência e desempenho profissional. Numa das questões bastante discutidas na atualidade, para o reconhecimento por desempenho no sistema educacional deste país, existem duas possibilidades, sendo a primeira a Asignación de Desempeño Variable por Desempeño Individual, ao qual podem se candidatar os professores que alcançarem pontuação destacada na avaliação docente; a segunda possibilidade é a Asignación de Excelencia Pedagógica, com o objetivo de reconhecer o mérito e a qualidade profissional de docentes do setor municipal e das escolas subvencionadas (Agusti \& Claro). Também o Equador adota a política de premiação do desempenho. A Lei Orgânica de Educação Intercultural (LOEI), de 2011, hierarquiza em 10 categorias as possibilidades de ascensão profissional, desde o ingresso na carreira até a última etapa da trajetória docente que contempla o tempo de serviço e o mérito. As categorias não privilegiam somente a antiguidade, como ainda a formação acadêmica, estudos de atualização e experiências angariadas, que devem ser demonstrados por processos de avaliação do desempenho (Ramia, 2014).

Na Argentina, que é uma República Federativa, a carreira é definida pelo Ministério da Educação em articulação com o Conselho Federal de Educação. Na política educacional desse país, algumas características chamam a atenção, como o Programa Nacional de Compensación Salarial Docente, que tem o objetivo de compensar as desigualdades entre as regiões. Sublinhe-se um aspecto interessante da carreira, que é a legislação que assegura aos docentes de instituições privadas, remuneração mínima igual aos docentes de instituições públicas. Registre-se ainda a existência de um piso de remuneração nacional que é estabelecido com base numa unidade de medida denominada Hora Cátedra, com valores diferentes entre os graus do ensino (Ganz, 2014). No Brasil, os estados e municípios têm autonomia para estruturar suas carreiras docentes, mas existe um piso salarial nacional que deve ser respeitado por todas as unidades federadas. Na Venezuela, não há um piso nacional, mas existe um salário base que é estabelecido na Convenção Coletiva do magistério, abrangendo as 6 categorias da carreira docente, sendo que a mudança de categoria depende do desempenho docente, ético e social e da formação continuada (Achkar, 2015).

Com relação à qualidade do ensino, os documentos produzidos pelos Ministérios da Educação dos países da Unasul mostram inovações e inúmeros esforços, cuja profundidade e extensão podem variar de um país para outro. Entre os pontos críticos nesse campo de estudos sobressaem a existência ou não de um currículo mínimo nacional e os sistemas de avaliação e acompanhamento. Na Argentina, está previsto 
na Lei de Educação Nacional (n. 26.206/2006) a definição de estruturas, conteúdos curriculares e núcleos de aprendizagem prioritários em todos os níveis da educação obrigatória, competindo ao Conselho Federal de Educação dar seguimento a essa disposição, constituindo ainda atribuição desse Colegiado o estabelecimento de diretrizes da avaliação nacional, que está sob a responsabilidade da Direção Nacional de Informação e Estatística Educativa (DENIECE), com o objetivo de dar "cuenta del desempeño de los alumnos en las asignaturas más importantes (lengua, matemática, ciencias sociales y ciencias naturales) en distintas etapas de su trayetoria educativa" (Ganz, 2014). A periodicidade pode variar de 2 a 3 anos mediante critério amostral.

No Chile, o Estado define um marco de objetivos e conteúdos comuns e obrigatórios para as diversas etapas da educação básica que asseguram uma mesma experiência formativa para a totalidade dos estudantes. Os padrões de qualidade compreendem os resultados obtidos na prova SIMCE (Sistema de Medición de Calidad de la Educación) que permite categorizar os alunos com base no currículo nacional, como ainda compreende resultados de qualidade durante o processo educativo, como autoestima e motivação, clima de convivência escolar, participação e formação cidadã, hábitos de vida saudável, equidade de gênero, entre outros fatores. O Simce inclui também a avaliação do desempenho docente feita a cada 4 anos, cujos resultados podem contemplar incentivos salariais (Agusti, Gusti \& Claro, 2014). O que chama a atenção no sistema educacional chileno não é somente a avaliação docente, como também a avaliação de processo em relação aos alunos, que inclui o desenvolvimento de valores fundamentais para a vida contemporânea e, certamente, poderá estar contribuindo para uma concepção mais humana de educação. Apesar da complexidade de estudos comparativos entre valores apontada por Wing On Lee e Maria Manzon, a sua importância vem sendo crescentemente reconhecida no contexto das incertezas e descaminhos existenciais contemporâneos, pois como afirmam esses estudiosos, a comparação pode mostrar surpresas como a constatação da divergência na convergência e da convergência na divergência (Lee \& Manzon, 2015). Gomes, num estudo sobre os valores solicitado pela Unesco, pergunta se, por séculos, as gerações foram educadas no preconceito e na memória de atos de barbaridade e se o processo educacional era tão poderoso para cultivar o ódio, por que não poderia ser igualmente influente para construir a paz? (Gomes, 2001). Talvez seja este um dos maiores desafios hodiernos das sociedades e de suas políticas de educação, que precisa ser considerado pelos países.

Nessa linha de movimento das ideias e considerando que a educação em valores humanos deve ocupar posição central nas políticas de qualidade da educação, vale a pena mencionar a experiência de alguns países da América do Sul, notadamente a Bolívia e o Equador, países com expressiva população indígena ou com descendência indígena. Nesses países, na primeira década do século XXI, no marco da crítica 
sobre o paradigma vigente de desenvolvimento, aos poucos foi sendo construído um discurso e conceito alternativos que inclui princípios de vida e cultura indígena como reciprocidade, solidariedade, complementaridade, dignidade, harmonia com a natureza, justiça social, bem-estar coletivo e individual. Esses princípios podem ser sintetizados na filosofia de "bem viver" ou "viver bem" e foram inseridos na Constituição e nas políticas de educação de ambos os países (Cepal, 2014). Na Bolívia, existem quatro princípios fundadores da política educacional, respectivamente, educação intra e intercultural e plurilinguismo, justiça social e erradicação da pobreza, equidade de gênero, e equilíbrio e harmonia com a natureza. Devido aos diversos povos indígenas que habitam o país, o currículo é intercultural e regionalizado, com a educação objetivando formação integral. A avaliação está sob a responsabilidade do Observatorio Plurinacional de la Calidad Educativa (OPCE) que tem, entre outras, a difícil missão de avaliar a participação e o grau de participação dos atores educacionais sobre a situação da qualidade da educação como meio e estratégia do processo de transformação e desenvolvimento do país para Viver Bem, que é diferente do Viver Melhor (Bolívia, 2014). Com base nesse pressuposto, também o Equador adotou como princípio e diretriz, a filosofia do Viver Bem. Todas as ações do Governo do Equador estão regidas com fundamentos nos Planos Nacionais de Bem Viver de duração quinquenal. Para assegurar a qualidade e elaborar indicadores de desempenho, o país possui o Instituto Nacional de Evaluación Educativa (INEE), como ainda o Instituto de Idiomas, Ciencias y Saberes Ancestrales de los Pueblos y Nacionalidades, com a missão de promover o uso e o desenvolvimento dos conhecimentos e experiências dos primeiros povos (Ramia, 2014). Face à necessidade de superar a distância entre a proclamação de princípios e os fatos, a Cepal recomenda a documentação, sistematização e intercâmbio de experiências (Cepal, 2014), ou seja, de estudos comparativos de preferência. Nesse sentido, a pedagogia do "viver bem" constitui tema promissor para estudos comparativos, pois, como afirmou Mark Mason, as comparações transculturais de educação não podem deixar de estudar nem a produção material nem os sistemas simbólicos. Um bom exemplo de algo que é ao mesmo tempo artefato material e um sistema simbólico é o currículo, como o são, também, as políticas educacionais e as matérias pedagógicas (Mason, 2015).

Com relação às políticas de financiamento, os países que cedo se conscientizaram sobre a importância de ampliar os investimentos, estão hoje entre as nações mais avançadas. As que não fizeram isso, submetem-se hoje aos efeitos de omissões do passado e encontram enormes dificuldades para ajustar seus orçamentos às demandas urgentes da educação (Cunha, no prelo), como é o caso do Brasil, que possui um enorme déficit em termos de qualidade e inclusão. É certo que nos últimos anos, na América Latina, via de regra, houve um aumento dos investimentos nada desprezível. De 4,5\% no ano 2000, o Produto Interno Bruto (PIB) subiu para 5,2\% em 2010, 
conforme dados de estudo Unesco (2015). Todavia, esses números não refletem as disparidades sociais e econômicas inter e intra países. Segundo o estudo referido, os países podem diferir muito em dimensões territoriais e populacionais e os investimentos podem ter critérios diferentes entre os vários graus e modalidades do ensino, o que torna necessário os estudos comparativos entre os países e as diversas regiões de um mesmo país.

Como o percentual do PIB converteu-se em referência, nos últimos tempos, alguns organismos internacionais, sobretudo a Unesco, a partir da Declaração Mundial de Educação para Todos, de Jomtien, Tailândia, 1990, tem procurado convencer os países para aumentarem os investimentos com base nesse indicador. Isso ocorreu com o Brasil, que chegou a investir em 2012 mais de 6\% do PIB na educação. Também na Argentina, por intermédio da Lei da Educação Geral de 2006, os investimentos foram ampliados para 6\% no mínimo do PIB nacional, com a adoção de critérios para determinar o montante de recursos para cada Província e para a Cidade Autônoma de Buenos Aires, o que contribuiu, segundo Casaño, para clarear as relações entre o governo central e os das províncias, pois o federalismo argentino sempre se caracterizou pelas desigualdades regionais. Foi para corrigir disparidades que o país criou o Programa Nacional de Compensação Docente (Casaño, 2015), mencionado anteriormente. Com preocupação semelhante, mas seguindo outro modelo, destaca-se a política de financiamento educacional do Chile. Consoante alguns estudiosos do tema, esse país colocou em prática uma experiência radical de privatização. Ao contrário de décadas anteriores, quando o governo central assumia o provimento de recursos para a educação, a reforma empreendida nas últimas décadas transferiu para o setor privado as escolas de ensino médio profissionalizantes e municipalizou o ensino infantil, fundamental e médio. Estabeleceu uma subvenção calculada por aluno atendido pelas municipalidades e incentivou a participação da comunidade e da iniciativa privada nas políticas escolares (Leal, Jesus \& Gomes, 2006). Assinale-se que a política de subvenção por aluno pode reduzir as disparidades e assimetrias entre as regiões. Por um outro modelo, o Plano Nacional de Educação do Brasil (PNE) 2014-2024 incluiu como meta a adoção de um indicador denominado custo-aluno-qualidade (CAQ) que permite o cálculo de quanto deve ser investido por estudante para garantir a indissociabilidade do trinômio qualidade-equidade-pertinência.

O Equador, país que vem se destacando nos últimos anos em várias políticas sociais, adotou um critério de aumento progressivo de recursos, com aumentos anuais de $0,5 \%$ até alcançar a meta de $6 \%$ do PIB. O critério de progressividade, se bem conduzido no conjunto das políticas públicas de modo a não sofrer retrocessos devido a fatores políticos ou econômicos, poderá permitir a consolidação gradual até atingir um ponto ótimo de estabilização, o que assegura a continuidade das políticas de educação com possibilidade de sua elevação para o status de política de Estado. Uma 
outra experiência que está a merecer estudos é a da Venezuela que, na fase áurea das commodities do petróleo, chegou a investir 7,37\% do PIB em 2009, possibilitando a inclusão de expressivos contingentes de crianças, jovens e adultos oriundos de segmentos pobres da população. Foi o período de criação das Missões Educativas Bolivarianas (Missões Robinson, Ribas e Sucre), em 2003, que tinha o objetivo de promover uma educação emancipadora para os venezuelanos. Essa experiência encerra muitas lições. Entre elas, o fato de que, na América Latina, a política educacional não pode estar sujeita às oscilações de governos e de mercado. Com a queda internacional do preço do petróleo, somado a impasses políticos internos, os investimentos em educação foram reduzidos, sendo que muitas das conquistas feitas poderão sofrer solução de continuidade. Uma lição importante da experiência venezuelana indica a necessidade de planejamento educacional elaborado a partir de uma concepção sistêmica de planejamento que considere os contextos internos e externos do país, sem o que dificilmente será possível assegurar a indispensável estabilidade de ações e políticas de desenvolvimento. Nunca será demais acrescentar que uma política de educação não se viabiliza independentemente da política global de um governo. Essa experiência indica ainda que a melhoria do ensino se, por um lado, é imprescindível ao desenvolvimento de um país, por outro, sinaliza que não poderá evoluir divorciada de pressupostos econômicos. Por melhor que sejam as intenções de uma política de educação, se deixar à margem as condições básicas de sua viabilização, certamente estará condenada ao fracasso. Milagres não se operam da noite para o dia. Se estes existem, são fruto de estabilidade democrática e da vontade coletiva de uma nação.

Nesse sentido, também da experiência do Brasil se podem extrair lições que, certamente, estudos comparativos ajudariam para a prevenção de erros e equívocos. No auge do preço de algumas commodities no mercado internacional (minério e soja), o Ministério da Educação chegou a ser considerado um Ministério de primeira linha, com crescentes investimentos, sobretudo na educação básica. Com a crise de 2008 e o declínio do ritmo de crescimento dos principais países importadores de commodities, seguido de crise política e econômica, os investimentos foram reduzidos. Em decorrência, a nova política econômica determinou o corte de $20 \%$ nos recursos vinculados à educação. As implicações que decorrem de reduções não somente colocam em risco projetos e programas em curso, como podem anular eventuais avanços. Será sempre oportuno lembrar que a educação é um setor que demanda continuidade, revisões e ajustes permanentes.

Como se pode observar, os caminhos são diferentes entre os países, com experiências e lições que podem ser aproveitadas em outros contextos. É certo que a observação de Hans deve estar sempre presente, qual seja, a de considerar a influência do passado, pois as nações modernas procuram modificar conscientemente o passado e criar um futuro melhor (Hans, 1971). Ademais, observa o autor, a aplicação 
dos resultados dos estudos foge à finalidade da educação comparada, situando-se no âmbito da administração e da gestão educacional. No entanto, ele argumenta que o estudo do passado histórico de várias nações apresenta frequentemente fatores comuns e, como seus ideais do futuro são consequência de movimentos universais, os problemas educacionais são semelhantes em muitos países e os princípios e as soluções que orientam as soluções tentadas podem ser comparados e mesmo identificados (Hans, 1971).

O reconhecimento de que os problemas educacionais são semelhantes em muitos países amplia a relevância dos estudos comparativos dos países da América Latina e, em especial, da América do Sul, que constitui o foco central do presente texto. Além disso, na medida em que os Ministérios da Educação da região sedimentarem a consciência sobre a relevância da cooperação e intercâmbio recíprocos, com o fomento e utilização simultânea de estudos comparados, certamente um fator importante de melhoria das políticas de educação emergirá e poderá converter-se em mecanismo propulsor de mudanças e inovações. Além disso, estudos comparativos com rigor metodológico poderão subsidiar as políticas de educação com evidências científicas, o que certamente poderá indicar caminhos e alternativas menos incertos.

\section{Notas}

1 Livro disponibilizado no site da Unasul sob o título: Estudos comparativos sobre a educação nos países da Unasul elaborado pelo autor.

\section{Referências}

Achkar, S. (2015). Estudio comparado de los sistemas educativos: propuesta de criterios de investigación UNASUR. Caracas: Ministerio de Educación. Mimeo.

Agusti, E. C., Gusti, E. C. \& Claro, J. P. (2014). Estudio comparado de los sistemas educativos: el caso de Chile. Santiago: Mineduc (Centro de Estudios). Mimeo.

Bethencourt, F. (2015). Racismos: das cruzadas ao século XX. Lisboa: Temas e debates: Círculo de Leitores.

Bolívia. (2014). Estudio comparado de los sistemas educativos. Bolívia: Ministério de la Educación. Mimeo.

Brasil. (2016). Brasil no Pisa 2015: sumário executivo. Brasília: Inep.

Brasil. (2015). Lei Darcy Ribeiro - 1996. LDB: Lei de Diretrizes e Bases da Educação Nacional. (11a ed). Brasília: Câmara dos Deputados.

Brasil. (2015). Plano Nacional de Educação(PNE) 2014-2024. Brasília: Câmara dos Deputados.

Carnoy, M. (2009). A vantagem acadêmica de Cuba: por que os alunos vão melhor na escola. São Paulo: Ediouro. 
Casaño, R.M.J. (2015). La ley n. 26.075 de financiamiento educativo y su incidencia en las finanzas públicas provinciales. Recuperado de Blog.eco.unc.edu.ar/jifp/files/45 jifp_t34.pdf

Castro, M.L.O. (2012). Brasil e Argentina: estudo comparativo das respectivas leis gerais sobre educação. Brasília: Senado Federal.

Cepal (2014). Los pueblos indígenas de América Latina. Santiago do Chile: Cepal.

Cepal (2016). Panorama social de América Latina 2015. Santiago do Chile: Nações Unidas-Cepal. Recuperado de http://repositorio.cepal.org/bitstream/handle/11362/39965/S1600175_es.pdf

Cepal (2017). Panorama social de América Latina 2017. Santiago: Cepal. Recuperado de https://www. cepal.org/pt-br/publicacoes/tipo/panorama-social-america-latina-caribe

Crossley, M. (2015). Repensando o contexto em educação comparada. In R. Cowen, A.M. Kazamias \& Unterhalter, E. (Orgs.). Educação comparada: panorama internacional e perspectivas (Vol. 2, pp. 629-646). Brasília: Unesco-Capes.

Cunha, C. (no prelo). Estudo comparativo dos sistemas educacionais dos países da UNASUL. Brasília: SASE-MEC.

Ganz, N. M. (2014). Proyecto estudio comparado de los sistemas educativos del Fondo de Iniciativas Comunes (FIC) del Consejo Suramericano de Educación de La Unión de Las Naciones Suramericanas (Unasur). Guión básico del diagnóstico nacional. Buenos Aires: Unasur. Mimeo.

Gomes, C.A. (2001). Dos valores proclamados aos valores vividos. Brasília: Unesco.

Hans, N. (1971). Educação comparada (2a ed.). São Paulo: Editora Nacional.

Kandel, I. L. (1960). Uma nova era em educação. Rio de Janeiro: Fundo de Cultura.

Kazamias, A. M. (2012). Agamenon contra Prometeu: globalização, sociedades do conhecimento/da aprendizagem e paideia na nova cosmópole. In Cowen, R. Kazamias, A. M. \& Unterhalter, E. (Orgs.). Educação comparada: panorama internacional e perspectivas (pp. 517-554). Brasília: UnescoCapes.

Krawczyk, N. R. \& Vieira, V. L. (2008). A reforma educacional na América Latina nos anos 1990: uma perspectiva histórico-sociológica. São Paulo: Xamã.

Leal, H. B., Jesus, W. F. \& Gomes, C. A. (2006). Financiación de la SEEC. In Anais del X Congreso de Educación Comparada del País Basco. S.Sebastian, Espanha, 2006(315-327).

Lee, W. O. \& Manzon, M. (2015). Comparações entre valores. In Bray, M., Adamson, B. \& Mason, M. (Orgs.). Pesquisa em educação comparada: abordagens e métodos (pp. 293-318). Brasília: Liber Livro; Cátedra Unesco.

Leung, F.K.S. \& Park, K. (2015). Comparações entre desempenhos pedagógicos. In Bray, M., Adamson, B. \& Mason, M. (Orgs.) Pesquisa em educação comparada: abordagens e métodos (pp.425-454). Brasília: Liber, Livro-Cátedra Unesco.

Marcuse, H. (2007). El hombre unidimensional. Barcelona: Ariel.

Mason, M. (2015). Comparações entre culturas. In Bray, M., Adamson, B. \& Mason, M. (Orgs.). Pesquisa em educação comparada: abordagens e métodos (pp. 255-292). Brasília: Liber Livro. 
Mehta, S. (2012). Pequenas e grandes histórias: para além das teorias em disputa: rumo ao 'multiálogo. In Cowen, R., Kazamias, A. M. \& Unterhalter, E. (Orgs.). Educação comparada: panorama internacional e perspectivas (pp. 647-669). Brasília: Unesco-Capes.

Mix, M.R. (2004). Los cien nobres de América. Córdoba, Argentina: Universidade Nacional de Córdoba (UNC).

Mix, M.R. (1992). América imaginaria. Barcelona: Editorial Lúmen.

Morin, E. (2000). Os sete saberes necessários à educação do futuro (2a ed.). São Paulo: Cortez. Brasília: Unesco.

Paulino, L.A. \& Pires, M.C. (2012). A título de conclusão: as perspectivas da América Latina no limiar do século XXI. In Mendonça, M.G. \& Pires, M.C. (Orgs.). Formação econômica da América Latina. São Paulo: LCTE.

Ramia, N. (2014). Estudio comparado de los sistemas educativos, el caso de Ecuador. Quito: Ministério de Educación. Mimeo.

Teodoro, A. (2016). Novas tecnologias de governação e reconfiguração dos modos de regulação das políticas de educação. In Cunha, C, Jesus, W.F. \& Souza, M.F.M. (Orgs.). Políticas de educação: cenários globais e locais (pp. 31-44). Brasília: UCB; Liber Livro.

Ramos, A. G. (1965). A redução sociológica (2a ed.). Rio de Janeiro: Tempo Brasileiro.

Touraine, A. (1989). Palavra e sangue. São Paulo: Trajetória Cultural. Campinas: Editora da Universidade Estadual de Campinas.

Unesco. (2015). Relatório de monitoramento global EPT. Brasília: Unesco.

Yang, R. (2015). Comparações entre políticas. In Bray, M., Adamson, B. \& Mason, M. (Orgs.). Pesquisa em educação comparada: abordagens e métodos (pp. 319-349). Brasília: Liber Livro.

Célio da Cunha

Doutor em Educação pela Unicamp. Ex-professor da Faculdade de Educação da Universidade de Brasília e ex-assessor da Unesco no Brasil. Atualmente é professor da Universidade Católica de Brasília.

E-mail: celio.cunha@gmail.com ORCID: orcid.org/0000-0002-9212-4208

\section{Correspondência}

Célio da Cunha

Universidade Católica de Brasília.

Campus I - QS 07 - Lote 01 - EPCT - Águas Claras - Brasília - DF CEP:

Data de submissão: Outubro 2017

Data de avaliação: Março 2018

Data de publicação: Setembro 2018 